\title{
Factors associated with serum antibodies to reticulin, endomysium, and gliadin in an adult population
}

\author{
S A McMillan, R P G Watson, E E McCrum, A E Evans
}

\begin{abstract}
Background-Gluten sensitivity is thought to be significantly under-diagnosed in the population.

Aims-The aims of this study were to investigate the prevalence of antibodies associated with coeliac disease in a large representative sample of the adult population and to determine factors that are associated with their presence.

Patients-Serum samples from 5420 subjects with approximately equal numbers in each five year group from ages 15 to 65 years were obtained from the Belfast MONICA project and Change of Heart surveys, set up to monitor and assess risk factors associated with coronary heart disease in the population.

Methods-Using immunofluorescence and enzyme linked immunosorbent assay (ELISA) techniques autoantibodies, including those to reticulin, endomysium, and gliadin were determined.

Results-The results establish that IgA antigliadin antibody prevalence is high at $5 \cdot 7 \%$. Antiendomysial antibody was present in $1.2 \%$ of samples and gliadin and endomysial antibodies in $0 \cdot 4 \%$. No significant differences were found between men and women, area of residence in Northern Ireland or the year of sampling over the eight year period. However, there was a significant increase in the prevalence of IgA gliadin antibody, and to a lesser extent IgA endomysial antibody, with increasing age.

Conclusion-The high prevalence of these positive antibodies suggests that coeliac disease may be relatively common in Northern Ireland.

(Gut 1996; 39: 43-47)
\end{abstract}

Keywords: coeliac disease, reticulin, endomysium, gliadin, antibodies.

Departments of

Medicine

R P G Watson

and Epidemiology and Public Health

E E McCrum

A E Evans

The Queens University of Belfast, Belfast

Correspondence to: Dr S A McMillan, Regional Immunology Laboratory, Belfast City Hospital Trust, Belfast BT9 7AD.

Accepted for publication 19 January 1996

Coeliac disease (CD) has been traditionally considered to be a disease of childhood and early adult life characterised by malabsorption, diarrhoea, weight loss, and failure to thrive. The disease can, however, be found at any age and in many cases is devoid of any of these 'typical' features, but is detected as a result of investigation of haematological abnormalities such as anaemia, macrocytosis, and folate deficiency. ${ }^{12}$ It is also recognised that there are a significant number of subjects with villous atrophy who are completely asymptomatic.
These include $10-15 \%$ of first degree relatives of known CD patients. ${ }^{34}$ It is therefore possible that a large number of people, perhaps the majority, remain undiagnosed and only the 'tip of the iceberg' of cases are recognised. ${ }^{5}$ Some of these will have non-specific but significant symptoms, which would benefit from treatment with a gluten free diet. ${ }^{6}$ Even in those who are asymptomatic there is evidence that they have significant bone problems ${ }^{7}$ and are at increased risk of developing malignancies, particularly of the gastrointestinal tract. $^{8}$ Treatment with a gluten free diet reduces the risk of lymphoma in $\mathrm{CD}^{9}$ and seems to produce improvement in bone mineralisation. ${ }^{10}$ It is consequently important to assess the full extent of gluten sensitivity in the population so that those at risk may benefit from treatment.

At present, a small bowel biopsy is the only definitive test for $\mathrm{CD}$. A reliable, less invasive test would facilitate screening of much larger numbers of people. A number of serological tests have been used as a pointer to diagnosis and include antireticulin antibody (ARA), antiendomysial antibodies (EMA), and antigliadin antibody (AGA), but their sensitivities and specificities have varied with assay methodology, the antibody isotype detected, and the patient group studied. ${ }^{11}$ IgA class AGA and EMA seem to give the best diagnostic performance ${ }^{12}$ and this combination has been suggested to be useful for population screening, by first testing for AGA and then confirmation with a positive IgA EMA. ${ }^{13}$

The aims of this study were to investigate the prevalence of antibodies associated with CD (ARA, EMA, and AGA) in a large representative sample of the adult population, and to determine factors that influence their presence. This is part of a larger study to investigate the relation between these antibodies and gluten sensitivity in the population.

\section{Methods}

\section{Study population}

In Northern Ireland the Belfast MONICA Project and Change of Heart Surveys were set up to determine risk factors associated with coronary heart disease in the population (MONICA: multinational MONItoring of trends and determinants in CArdiovascular disease). The Belfast MONICA Project comprised three population sampling studies each extending over approximately a one year period during 1983/4, 1987/8, and 1991/2. 
The study population was selected from Belfast, Castlereagh (an urban area adjacent to Belfast), North Down and Ards District Councils. These last two areas contained both urban and rural communities. The Change of Heart Survey ${ }^{14}$ was a similar project undertaken in 1988 with the sampling area outside that of the Belfast MONICA Project and included the remainder of Northern Ireland. These populations were selected as single random samples stratified by sex and 10 year age groups from 12-65 years by computer program from patients contained on the Northern Ireland Central Service Agency's General Practitioners list and totalled 15992 subjects. From these subjects 7617 agreed to take part in the surveys. Serum samples were available to use from 5420 subjects, aged 15 to 65 years, of this screened population, 2665 men and 2755 women. Our study group contained approximately equal numbers of men and women in each five year age interval $\left(\chi^{2} 15 \cdot 3, p=0.08\right)$. Information on age, sex, year of sampling, and area of residence was also available.

\section{Detection of autoantibodies}

Serum samples stored at $-70^{\circ} \mathrm{C}$ were obtained as described above and tested for specific autoantibodies over a four month period. Using indirect immunofluorescence serum samples were initially screened at a dilution of $1 / 20$ for the presence of antireticulin of the $R 1$ type (ARA), antinuclear (ANA), antimitochondrial (AMA), antismooth muscle (SMA), and antigastric parietal cell antibodies (GPCA) using composite sections of rat liver, kidney, and mouse stomach (BioDiagnostics, Worcestershire, UK) and fluorescein conjugated antihuman globulin (Dako, Buckinghamshire, UK). Any serum containing positive autoantibodies were further titrated. Sera containing ARA were titrated for both IgG and IgA antibodies. Endomysial antibody (EMA) in the IgA class was detected by indirect immunofluorescence using monkey oesophagus (BioDiagnostics, Worcestershire, UK) as antigen. ${ }^{11}$ Sera were initially tested at a dilution of $1: 2$ and any positives tested at dilutions 1:5, 1:10, and $1: 20$. Positivity was taken as a titre of $1: 5$ or greater. IgA antigliadin antibody (AGA) was

TABLE I Prevalence of coeliac antibodies and combinations of these antibodies in the study population, $n=5420$

\begin{tabular}{lc}
\hline Antibody & Number (\%) positive \\
\hline IgA ARA & $43(0 \cdot 8)$ \\
IgA EMA & $65(1 \cdot 2)$ \\
IgA AGA & $307(5 \cdot 7)$ \\
IgA ARA+IgA EMA & $12(0 \cdot 2)$ \\
IgA AGA+IgA EMA & $20(0 \cdot 4)$ \\
IgA ARA+IgA AGA & $4(0 \cdot 1)$ \\
IgA ARA+IgA EMA+IgA AGA & $12(0 \cdot 2)$ \\
\hline
\end{tabular}

TABLE II Coeliac antibodies and sex of subjects

\begin{tabular}{|c|c|c|c|}
\hline \multirow[b]{2}{*}{ Antibody } & \multicolumn{2}{|c|}{ Number (\%) positive in } & \multirow[b]{2}{*}{$\chi^{2}$ Test } \\
\hline & $\begin{array}{l}\text { Males } \\
(n=2665)\end{array}$ & $\begin{array}{l}\text { Females } \\
(n=2755)\end{array}$ & \\
\hline $\begin{array}{l}\text { IgA ARA } \\
\text { IgA EMA } \\
\text { IgA AGA }\end{array}$ & $\begin{array}{r}20(0 \cdot 8) \\
32(1 \cdot 2) \\
161(6 \cdot 0)\end{array}$ & $\begin{array}{r}23(0 \cdot 8) \\
34(1 \cdot 2) \\
146(5 \cdot 3)\end{array}$ & $\begin{array}{l}0 \cdot 3, p=0.61 \\
0 \cdot 1, p=0.81 \\
1 \cdot 4, p=0.24\end{array}$ \\
\hline
\end{tabular}

measured by enzyme linked immunosorbent assay (ELISA; Labmaster, Turku, Finland). Results were expressed in ELISA units (EU) with a normal range of 0-99 $(97 \cdot 5$ th centile).

\section{Data storage and statistical analysis}

A database was established (SPSS/PC+, SPSS Inc 1988) to store information for each subject, this included survey identification number, age, date of birth, sex, area of residence in Northern Ireland, and the results of the various autoantibodies tested. All statistical analyses were performed using a SPSS/PC+ statistical package. $\chi^{2}$ Analysis was used to compare the proportion with and without the antibody between subgroups. The Mantel-Haenszel test for linear trends was also used. A $p$ value $<0.05$ was considered statistically significant.

\section{Results}

Prevalence of coeliac antibodies

Table I shows the prevalence of the $C D$ associated antibodies (ARA, EMA, AGA) in the study population. IgA AGA showed the highest prevalence at $5 \cdot 7 \%$ (307 of 5420 ). IgA EMA occurred in $1.2 \%$ and a combination of IgA AGA and IgA EMA was found in $0.4 \%$ of the samples. Of the 65 sera with a positive IgA EMA, 18 had a titre of $1: 5$ and $47(0.9 \%)$ had titres of $1: 20$ or greater. IgG ARA was found in $25(0.5 \%)$ of the sera and IgA ARA in 24 $(0.4 \%)$, both isotypes were present in a further $19(0.4 \%)$ sera. ARA, EMA, and AGA were also detected on their own in the serum samples; $30 \%$ (13 of 43 ) of the positive IgA ARA samples had no other CD associated antibodies present. Similarly $25 \%$ (16 of 65 ) positive IgA EMA and $89 \%$ (272 of 307) positive IgA AGA were also detected on their own.

The prevalence of other autoantibodies were: ANA (1.9\%), SMA (0.8\%), AMA $(0.4 \%)$, and GPCA $(4.5 \%)$. The prevalence of both ANA and GPCA increased with age. No association was found between the presence of these autoantibodies and any of the CD associated antibodies. Serum IgA concentrations were determined in 2000 subjects and the incidence of IgA deficiency was 1:500. None of these IgA deficient patients had IgG ARA. There was no association between positive serology and serum concentrations of immunoglobulins.

Prevalence of coeliac antibodies and sex of subjects There was no difference between the prevalence of these antibodies in men and women (Table II).

\section{Prevalence of coeliac antibodies and year of sampling}

There was no significant difference between the prevalence of the $\mathrm{CD}$ associated antibodies obtained at the three time periods, although the prevalence of IgA ARA, EMA, and 
TABLE III Coeliac antibodies and year of sampling

\begin{tabular}{lllll}
\hline & \multicolumn{2}{l}{ Number (\%) positive in different years of sampling } & \\
\cline { 2 - 4 } Antibody & $1983 / 4(n=1206)$ & $1987 / 8(n=2390)$ & $1991 / 2(n=1824)$ & $x^{2}$ Test \\
\hline IgA ARA & $12(1 \cdot 0)$ & $17(0 \cdot 7)$ & $14(0 \cdot 8)$ & $3 \cdot 4, \mathrm{p}=0 \cdot 18$ \\
IgA EMA & $19(1 \cdot 6)$ & $24(1 \cdot 0)$ & $23(1 \cdot 3)$ & $2 \cdot 6, \mathrm{p}=0 \cdot 27$ \\
IgA AGA & $80(6 \cdot 6)$ & $130(5 \cdot 4)$ & $97(5 \cdot 3)$ & $5 \cdot 5, \mathrm{p}=0 \cdot 06$ \\
\hline
\end{tabular}

TABLE IV Coeliac antibodies and area of residence within Northern Ireland

\begin{tabular}{lccccc}
\hline \multicolumn{5}{c}{ Number $(\%)$ positive in different areas of residence } \\
\cline { 2 - 5 } Antibody & $\begin{array}{l}\text { Area } 1 \\
(n=45)\end{array}$ & $\begin{array}{c}\text { Area } 2 \\
(n=2596)\end{array}$ & $\begin{array}{l}\text { Area 3 } \\
(n=676)\end{array}$ & $\begin{array}{c}\text { Area } 4 \\
(n=1693)\end{array}$ & $\chi^{2}$ Test \\
\hline IgA ARA & $4(0.9)$ & $23(0.9)$ & $8(1 \cdot 2)$ & $8(0.5)$ & $4 \cdot 8, \mathrm{p}=0 \cdot 18$ \\
IgA EMA & $8(1 \cdot 8)$ & $35(1 \cdot 3)$ & $11(1 \cdot 6)$ & $12(0.7)$ & $7 \cdot 1, \mathrm{p}=0.07$ \\
IgA AGA & $20(4 \cdot 4)$ & $157(6.0)$ & $49(7 \cdot 2)$ & $81(4 \cdot 8)$ & $8 \cdot 1, \mathrm{p}=0.09$
\end{tabular}

Area 1: Ards District. Area 2: Belfast and Castlereagh. Area 3: North Down District. Area 4: Outside Greater Belfast Area.

TABLE V Coeliac antibodies and age of subjects

\begin{tabular}{|c|c|c|c|c|c|c|}
\hline \multirow[b]{2}{*}{ Antibody } & \multicolumn{5}{|c|}{ Number (\%) positive in different age groups (years) } & \multirow[b]{2}{*}{$\chi^{2}$ Test } \\
\hline & $\begin{array}{l}15-25 \\
(n=723)\end{array}$ & $\begin{array}{l}26-35 \\
(n=994)\end{array}$ & $\begin{array}{l}36-45 \\
(n=1234)\end{array}$ & $\begin{array}{l}46-55 \\
(n=1332)\end{array}$ & $\begin{array}{l}56-65 \\
(n=1137)\end{array}$ & \\
\hline $\begin{array}{l}\text { IgA ARA } \\
\text { IgA EMA } \\
\text { IgA AGA }\end{array}$ & $\begin{array}{r}4(0 \cdot 6) \\
8(1 \cdot 1) \\
18(2 \cdot 5)\end{array}$ & $\begin{array}{r}8(0 \cdot 8) \\
9(0 \cdot 9) \\
44(4 \cdot 4)\end{array}$ & $\begin{array}{l}11(0.9) \\
16(1 \cdot 3) \\
72(5 \cdot 8)\end{array}$ & $\begin{array}{r}9(0 \cdot 7) \\
14(1 \cdot 1) \\
82(6 \cdot 2)\end{array}$ & $\begin{array}{l}11(1 \cdot 0) \\
19(1 \cdot 7) \\
91(8 \cdot 0)\end{array}$ & $\begin{array}{c}3.6, p=0.5 \\
5.8, p=0.09 \\
38.4, p<0.0001\end{array}$ \\
\hline
\end{tabular}

AGA appeared slightly higher at the $1983 / 4$ sampling period (Table III).

Prevalence of coeliac antibodies and area of residence of subjects

The prevalence of the $\mathrm{CD}$ antibodies was not significantly different when the four geographical areas of residence of the subjects

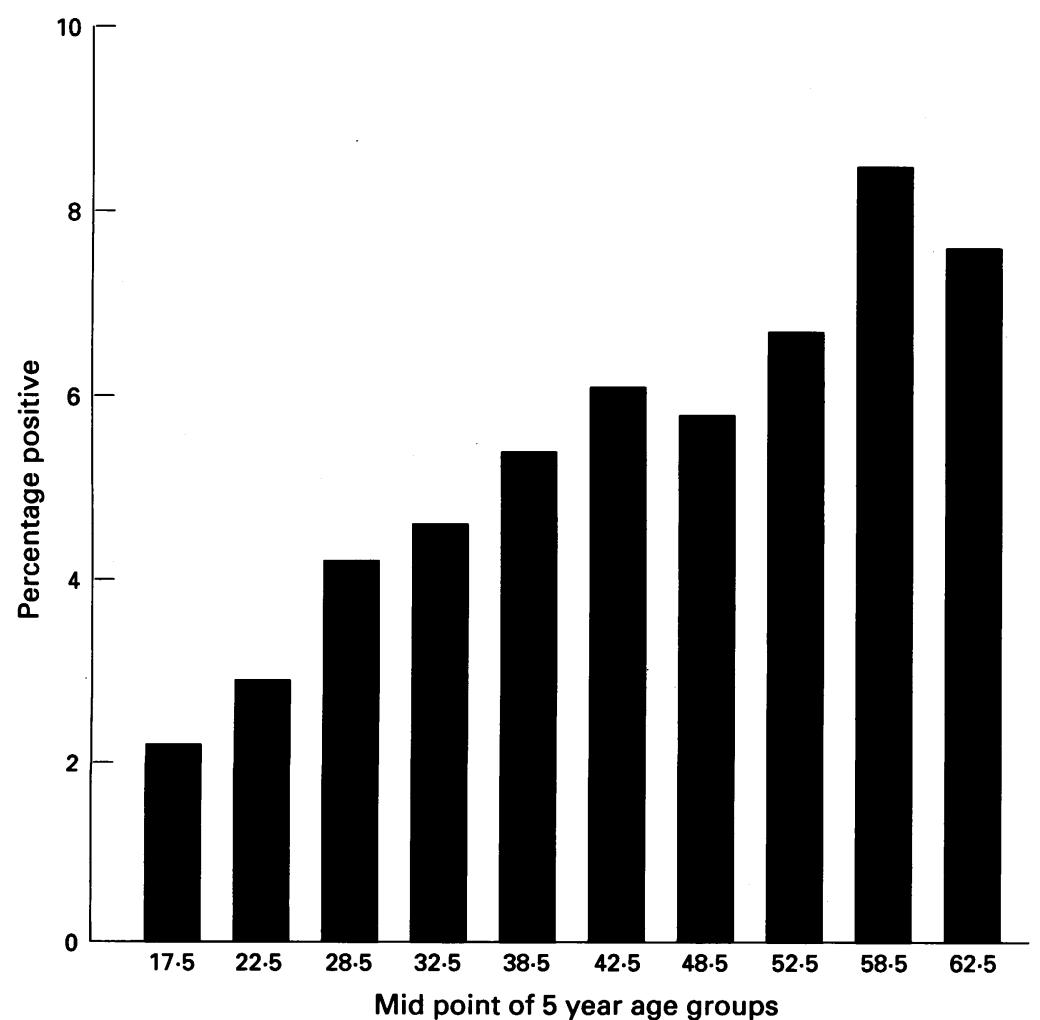

Increase in percentage positivity of IgA $A G A$ with age. Subjects are in five year age groups from 15-20 years to 60-65 years. within Northern Ireland were taken into account (Table IV).

\section{Prevalence of coeliac antibodies and age of subjects}

The prevalence of IgA ARA was not significantly different between the age groups. However, the prevalence of IgA AGA showed a statistically significant increase with age $(p<0.0001)$ with $2.5 \%$ positivity in the $15-25$ years age group rising to $8.0 \%$ in the $55-65$ years age group (Table V, Figure). The Mantel-Haenszel test indicated that this increase was linear. The prevalence of IgA EMA seemed to rise with age but this was not shown to be statistically significant, however, when the subjects were divided into below and above 35 years there was a significantly greater number of subjects with IgA EMA in the older group than in the younger group $(1.4 \%$ $\left.v 0 \cdot 8 \% ; \chi^{2}=3 \cdot 8, \mathrm{p}=0.04\right)$.

\section{Discussion}

As part of a comprehensive assessment of the prevalence and clinical profile of adult CD in the Northern Ireland population we have studied the prevalence of IgA ARA, IgA EMA, and IgA AGA in a large number of adult subjects, aged between 15 and 65 years and examined a number of potential factors influencing their presence. Northern Ireland consists of a comparatively stable ethnic community of approximately 1.5 million making it a good population to study disease incidence and prevalence. The Belfast MONICA Project and Change of Heart surveys were established to assess risk factors for coronary heart disease and provided us with a large sample of the Northern Ireland population. This is the largest study of its kind in the literature, and in contrast with other similar studies, is representative of the entire adult population over a wide age range and not limited to healthy volunteers such as blood donors.

Although the presence of positive serology does not exactly correlate with clinical CD, certain antibodies do show good sensitivities and specificities for the disease. We have found in patients with a high suspicion of $C D$ attending a gastroenterology clinic the sensitivity and specificity of IgA AGA and IgA EMA to be $100 \%, 100 \%$ and $89 \%$ and $100 \%$ respectively, for biopsy confirmed CD. ${ }^{11}$ Preselecting a patient group increases the prevalence of the disease in that group and it is known that a pronounced increase in test predictive value occurs when there is a rise in the prevalence of the disease under study. ${ }^{15}$ Our experience would indicate that sensitivity, specificity, and predictive values for IgA EMA and especially IgA AGA are lower in patients from sources other than gastroenterology clinics than in those from preselected high prevalence disease groups. A combination of a positive IgA AGA together with a positive IgA EMA is regarded as being indicative of $\mathrm{CD},{ }^{11}$ this combination was found in $0.4 \%$ of subjects, suggesting a prevalence of CD of 1 in 250. IgA EMA on its 
own has also been shown to have a high predictive value for $\mathrm{CD}^{11}{ }^{16-18}$; and in our study $1 \cdot 2 \%$ ( 1 in 83 ) had this antibody. Most laboratories test for IgA EMA at a dilution of 1:5, however, the titre of IgA EMA in patients with $\mathrm{CD}$ is usually much higher. In our population $47(0.9 \%)$ had a titre of $1: 20$ or greater. A clinical follow up of these patients will determine the true sensitivity and specificity of positive serology in the adult population.

In our study population IgA AGA was detected in $5.7 \%$ ( 1 in 18 ) subjects. The relevance of a positive AGA has been the subject of a number of reports. In a study of blood donors Grodzinsky et al ${ }^{19}$ detected AGA in 49 of 1866 donors aged between 18 and 64 . Seven of these 49 showed small bowel enteropathy characteristic of CD. The same group found after a six year follow up that none of the 42 AGA positive subjects with normal histology had detectable EMA or any major symptoms compatible with CD. They also found that in approximately one third, the high AGA values had returned to normal. ${ }^{20}$ Our preliminary results would indicate that a number of our positive IgA AGA subjects have in time also returned to normal values suggesting that a limited IgA AGA response is not uncommon in the healthy population and that the presence of a prolonged IgA AGA response is a better indicator of $\mathrm{CD}$. In an Italian study comprising 3351 students from a secondary school population aged 11-15 years, 71 were found to have positive AGA serology. Further investigation of this group showed 11 to have $C D$, although most had no serious symptoms. ${ }^{13}$ It seems that only a fraction of positive AGA patients have clinical CD. However, in recent years it has been proposed that gluten sensitivity encompasses a histological spectrum ranging from inflammatory cell infiltrate to severe atrophy. ${ }^{21}$ There is evidence that serological markers may be associated with mild changes or predict the future development of atrophy. O'Farrelly et al 22 showed that patients with positive $\alpha$ gliadin antibody and apparently normal bowel architecture, had high intraepithelial lymphocyte counts consistent with an immunological response, and which may be equivalent to the early type 1 infiltrative lesion of gluten sensitivity described by Marsh. ${ }^{21}$ Collins et al ${ }^{23}$ showed that after a follow up period of between one and seven years, seven of 25 patients who previously had positive ARA or AGA but with normal small bowel mucosa, had developed small bowel villous atrophy.

Many factors may be responsible for predisposition to $C D$ and its subsequent modification. These include genetic, environmental, dietary, geographical, and immunological reactivity. We investigated a number of factors in relation to the prevalence of $C D$ associated antibodies. There was no difference in the prevalence of the antibodies between men and women even at different ages. Although there is evidence from several published series that $\mathrm{CD}$ is more common in adult women than men, ${ }^{12}$ it is not clear whether this is due to a true difference in disease prevalence or if there is a significant difference in case ascertainment between men and women. Our results suggest the second of these may be the case. In our study the prevalence of IgA EMA and more strikingly IgA AGA increased with age. A similar increase in IgA AGA has been described in blood donors aged between 18 and $65 .{ }^{24}$ It was suggested that this is a reflection of changed immunological reactivity in the gut with age. ${ }^{19}$ The age related prevalence of AGA may reflect a similar pattern of gluten sensitivity, and is supported by reports of the prevalence of adult CD from two Swedish studies. In one the highest prevalence was found in the age group 65-74 years and the lowest between ages 15-24 years, ${ }^{25}$ while in the other study the peak prevalence was shown to occur between ages 45-54. ${ }^{26}$ However, this was not found in the prevalence study of $\mathrm{CD}$ in the Lothian district of Scotland by Logan et al where the age distribution of patients was even throughout the age range up to 64 years. ${ }^{27}$ The prevalence of the other autoantibodies is similar to that previously reported in healthy populations, ${ }^{28}$ however, no correlation was seen between the $C D$ antibodies and these autoantibodies. As with the IgA AGA and IgA EMA the prevalence of ANA and GPCA also increased with age maybe reflecting loss of immunological tolerance to these antigens.

Samples were obtained from four different geographical locations within Northern Ireland representing distinct urban and rural areas. No differences were seen in the prevalence of antibodies from the different areas, which suggests that $C D$ is similar throughout the country. Previous geographical comparisons of $\mathrm{CD}$ prevalence between countries have shown considerable differences. ${ }^{27}$ Although ethnic differences may account for some of the variation it is probable that differences in case ascertainment also contribute. This was thought to be the principal reason for the reported variation in $\mathrm{CD}$ prevalence between different regions of England. ${ }^{1}$ It was suggested that $C D$ was significantly underdiagnosed in some areas. Our data, by analogy and extrapolation, supports this notion.

Our results show that the prevalence of all the CD associated antibodies tested in 1983/4, $1987 / 8$, and $1991 / 2$ has remained relatively stable over this period. This suggests the prevalence of CD may also be stable over this period, and supports the contention that the reported increase in the incidence of adult $C D$ in recent years is due to better recognition of the condition rather than a real increase. ${ }^{2} 29$

The prevalence of CD in Europe based on symptomatic cases has been estimated to be between 1:330 and 1:1000. ${ }^{12}$ Data from our study on the prevalence of positive antibodies in the Northern Ireland population suggest a higher prevalence. We now intend to follow up subjects with positive serology to determine the degree of correlation with gluten sensitivity. If it shows large numbers of subjects who would benefit from a gluten free diet it will have important implications for the future recognition of the condition and perhaps routine population screening. 
This study was supported by a grant from the Northern Ireland Department of Health and Social Services.

1 Swinson CM, Levi AJ. Is coeliac disease under diagnosed? $B M \Im$ 1980; 281: 1258-60.

2 Logan RFA, Turner G, Rifkind EA, Heading RC, Ferguson A. Changes in clinical features of coeliac disease in adults in Edinburgh and the Lothians 1969-79. BMF 1983; 286: 95-7.

3 MacDonald WC, Dobbins WO, Rubi CE. Studies of the familial nature of coeliac sprue using biopsy from the small intestine. N Engl f Med 1965; 272: 448-56.

4 Stokes PL, Ferguson R, Holmes GKT, Cooke WT. Familial aspects of coeliac disease. $Q \mathcal{F} \mathrm{Med} 1976 ; 45: 567-82$

5 Auricchio S, Visakorpi JK. Common food intolerances 1: Epidemiology of coeliac disease. Workshop Capri 11-12 Oct 1991. Basel: S Karger, 1992.

6 Watson RGP, McMillan SA, Dickey W, Biggart JD, Porter KG. Detection of undiagnosed coeliac disease with atypical features using antireticulin and antigliadin antibodies. Qf Med 1992; 305: 713-8.

7 Mazure R, Vazquez H, Gonzalez D, Mautalen C, Pedreira $\mathrm{S}$, Boerr $\mathrm{L}$, et al. Bone mineral affection in asymptomatic adult patients with celiac disease. Am $\mathcal{F}$ Gastroenterol 1994; 89: $2130-4$.

8 Stokes PL, Prior P, Sorahan TM, McWalter RJ, Waterhouse JAH, Cooke WT. Malignancy in relatives of patients with coeliac disease. Br F Prev Soc Med 1976; 30: $12-21$.

9 Holmes GKT, Prior P, Lane MR, Pope D, Allan RN. Malignancy in coeliac disease - effect of a gluten free diet. Mutignancy in coeliac

10 McFarlane XA, Bhalla AK, Reeves DE, Morgan LM, Robertson DAF. Osteoporosis in treated adult coeliac Robertson DAF. Osteoporos
disease. Gut 1995; 36: 710-4.

11 McMillan SA, Haughton DJ, Biggart JD, Edgar JD, Porter KG, McNeill TA. Predictive value for coeliac disease of antibodies to gliadin, endomysium, and jejunum in patients attending for jejunal biopsy. $B M \mathcal{F}$ 1991; 303: 1163-5.

12 Corrao G, Corazza GR, Andreani ML, Torchio P, Valentini $\mathrm{RA}$, Galatola $\mathrm{G}$, et al. Serological screening of coeliac disease: choosing the optimal procedure according to disease: choosing the optimal procedure acco

13 Catassi C, Rätsch I-M, Fabiani E, Rossini M, Bordicchia F, Candela F, Coppa GV, et al. Coeliac disease in the year 2000: exploring the iceberg. Lancet 1994; i: 200-3.

14 Evans AE, McCrum EE, Patterson CC. The change of heart baseline clinical survey. A report to the Health Promotion Agency. Belfast: The Queen's University of Belfast, 1990

15 Gallen RS. Use of predictive value theory in clinical immunology. In: Rose NR, Friedman H, Fahey FL, eds.
Manual of clinical laboratory immunology. 3rd ed. Washington: American Society for Microbiology, 1986: 966-71

16 Visakorpi JK, Mäki M. Changing clinical features of coeliac disease. Acta Paediatr 1994; (suppl 395): 10-3.

17 Hällström $O$. Comparison of IgA-class reticulin and endomysial antibodies in coeliac disease and dermatitis herpetiformis. Gut 1989; 30: 1225-32.

18 Lerner A, Kumar V, Iancu TC. Immunological diagnosis of childhood coeliac disease: comparison between antigliadin, antireticulin and antiendomysial antibodies. Clin Exp Immunol 1994; 95: 78-82.

19 Godzinsky E, Franzen L, Hed J, Ström M. High prevalence of celiac disease in healthy adults revealed by antigliadin antibodies. Ann Allergy 1992; 69: 66-70.

20 Valdimarsson T, Ström M, Grodzinsky E, Hed J, Skogh T. Six year follow up of healthy subjects with high antigliadin antibodies. Scand $\mathcal{F}$ Gastroenterol 1992; 27 (suppl gliadin an 69 .

21 Marsh MN. Mucosal pathology in gluten sensitivity. In: Marsh MN, ed. Coeliac disease. Oxford: Blackwell Scientific, 1992: 136-91.

22 O'Farrelly C, Graeme-Cook F, Hourihane D O'B, Feighery C, Weir DG. Histological changes associated with wheat protein antibodies in the absence of villous atrophy. $\mathcal{F}$ Clin Pathol 1987; 40: 1228-30.

23 Collins P, Helin H, Mäki M, Hallström O, Karvonen A-L. Follow-up of patients positive in reticulin and gliadin antibody tests with normal small-bowel biopsy findings. Scand f Gastroenterol 1993; 28: 595-8.

24 Grodzinsky E, Hed J, Lieden G, Sjogren F, Strom M. Presence of IgA and IgG antigliadin antibodies in healthy adults as measured by micro-ELISA. Effect of various adults as measured by micro-ELISA. Effect of various
cutoff levels on specificity and sensitivity when diagnosing coeliac disease. Int Arch All Appl Immunol 1990; 92: 119-23.

25 Midhagen G, Jarnerot G, Kraaz W. Adult coeliac disease within a defined geographic area in Sweden. Scand $\mathcal{F}$ Gastroenterol 1988; 23: 1000-4.

26 Hallert C, Gotthard R, Norrby K, Walan A. On the prevalence of adult coeliac disease in Sweden. Scand $\mathcal{7}$ Gastroenterol 1981; 16: 257-61.

27 Logan RFA. Epidemiology of coeliac disease. In: Marsh MN, ed. Coeliac disease. Oxford: Blackwell Scientific, 1992: 192-214.

28 Shoenfeld Y, Isenberg D. The mosaic of autoimmunity (The factors associated with autoimmune disease). Research monographs in immunology. Vol 12. Amsterdam: Elsevier, 1989.

29 Sategna-Guidetti C, Grosso S. Changing pattern in adult coeliac disease: a 24-year survey. Eur $\mathcal{f}$ Gastroenterol Hepatol 1994; 6: 15-9. 